\title{
Ergo-Anthropometrics: Joining Fit to Fat to Predict Cardiovascular Risk
}

\author{
By Alberto Morales MD MPH
}

It is well known that fat is a metabolically active endocrine organ involved in production of numerous prothrombotic and proinflammatory substances. Excess intra-abdominal adiposity in particular is linked to multiple cardiometabolic risk factors.

However, the precise relationship between obesity and risk of coronary heart disease (CHD) is the subject of debate, due to obesity's limited predictive value for such risk, the wide range of confounding co-morbidities among obese persons, and limitations to clinical assessment of obesity. Various anthropometric methods have been used as clinical measurements for obesity: the most universally accepted today are body mass index (BMI), waist circumference, and waist-hip ratio.

One of the main limitations of these clinical tools is their failure to discriminate between fat and lean body mass (muscle). For example, a BMI of $35 \mathrm{~kg} / \mathrm{m}^{2}$ could describe a high-performance athlete as well as a sedentary obese individual. Thus, some authors suggest that, ideally, obesity should be expressed as a percent of body fat ( $>25 \%$ in men and $>35 \%$ in women).

Yet, I would argue that we need a more comprehensive tool to improve clinical assessment for disease risk prediction-one that combines the main anthropometric measures with levels of physical activity. This would also single out inactive obese individuals who theoretically would have a greater percentage of body fat and cardiovascular disease (CVD) risk.

\section{...we need a more comprehensive tool to improve clinical assessment for disease risk prediction}

This notion is supported in part by two important epidemiological studies of coronary heart disease: the Nurses' Health Study, involving a cohort subset of 88,393 women;[1] and the Women's Health Study, with a cohort of 38,987 women.[2] Their research found that coronary heart disease risk increased progressively through the following groups: normal weight-active; normal weight-inactive; obese-active; and obese-inactive.

Based on these studies and other evidence allowing extrapolation to men, I have recently proposed an ergo-anthropometric classification, and accompanying scoring method, which combines anthropometric and physicial activity measurements. In previous publications.[3,4]

I have outlined advantages of this classification over the traditional approach of the American National Heart, Lung and Blood Institute; and in response to this proposal, experts such as Carl J. Lavie (Ochsner Medical Center, New Orleans, USA) and Justo Sierra-Johnson (Mayo Clinic, Rochester, USA) have commented that "methods other than BMI may be better to detect overweightness/obesity and predict increased medical and CVD risk."[4]

Arguments against adopting an ergo-anthropometric paradigm stem primarily from reports of the "obesity paradox," in which, contrary to experience in primary prevention, research shows that in secondary prevention for conditions such as cardiac insufficiency and coronary syndrome, obese patients have better prognoses than normal-weight patients. Nevertheless, the largest study relating mortality to BMI (pooled data from 19 prospective studies among 1.46 million non-Hispanic white adults in the USA) revealed that overweight and obesity are associated with increases in all-cause mortality.[5] It should also be noted that certain biases may have been introduced in studies reporting the obesity paradox, since such research does not always include multivariate analysis of important predictive factors related to renal function, clinical severity of acute events, biomarkers, and complex pharmacological variables.

Consider the INTERHEART Study, carried out in 52 countries, which detected physical inactivity and obesity as two of the nine factors that account for $90 \%$ of the risk of acute myocardial infarction.[6] What value would be added to such a study by using ergo-anthropometric scoring to calculate the joint predictive influence of these two factors-giving fuller consideration to their interaction?

Such a combined approach has the potential to equip the medical community with an instrument that permits more integrative research-but most importantly, more holistic strategies in the prevention of the world's most prevalent, deadly and preventable non-communicable chronic diseases. $-1 /$ -

1. Li TY, Rana JS, Manson JE, Willett WC, Stampfer MF, Colditz GA, et al. Obesity as compared with physical activity in predicting risk of coronary heart disease in women. Circulation. 2006;113(4):499-506.

2. Weinstein AR, Sesso HD, Lee IM, Rexrode KM, Cook NR, Manson JE, et al The joint effects of physical activity and body mass index on coronary heart disease risk in women. Arch Intern Med. 2008;168(8):884-90.

3. Morales Salinas A, Coca A. Obesidad, actividad física y riesgo cardiovascular: clasificación ergo-antropométrica, variables farmacológicas, biomarcadores y "paradoja del obeso". Med Clin(Barc). 2010;134(11):492-8. Spanish.

4. Morales Salinas A, Coca A. Ergo-anthropometric Assessment. (letter and reply). Mayo Clin Proc. 2009;84(10):939-42.

5. Berrington de Gonzalez A, Hartge P, Cerhan JR, Flint AJ, Hannan L, Maclnnis RJ, et al. Body-Mass Index and Mortality among 1.46 Million White Adults. N Engl J Med. 2010;363:2211-19.

6. INTERHEART Study Investigators. Effect of potentially modifiable risk factors associated with myocardial infarction in 52 countries (The INTERHEART Study): case control study. Lancet. 2004;113(4):499-506.

Submitted: December 5, 2010

Approved for publication: March 15, 2011

Disclosures: None 